(с) И.И. Дедов, М.В. Шестакова*

Национальный медицинский центр эндокринологии, Москва

Открытие инсулина и начало его использования в 1921-1922 гг. совершили переворот как в эндокринологии, так и медицине в целом. Это знаменательное событие подарило миллионам больных сахарным диабетом не только саму возможность жить, но и надежду на то, чтобы жизнь с этим заболеванием была полноценной.

В статье рассматриваются история открытия инсулина, а также эволюция нескольких поколений препаратов этого гормона и тех преимуществ каждого из поколений, которые кардинальным образом изменили не только продолжительность жизни, но и ее качество.

Первое поколение - инсулины животного происхождения и решения первых задач по их достаточному производству и очистке. Следующее поколение - человеческие инсулины, очистка которых также была важной проблемой. Третье поколение - аналоги инсулина, действие которых стало ближе к профилю действия природного инсулина. И последнее поколение - аналоги инсулина, наиболее близко имитирующие действие инсулина человека.

Наряду с развитием препаратов инсулина в статье прослеживается эволюция средств его введения.

КЛЮЧЕВЫЕ СЛОВА: инсулин; 100 лет; аналоги

\title{
ON THE CENTENARY OF THE INSULIN DISCOVERY
}

\author{
(c) Ivan I. Dedov, Marina V. Shestakova
}

Endocrinology Research Centre, Moscow, Russia

The discovery of insulin and the beginning of its use in 1921-1922 made a revolution in endocrinology and in medicine in general. This significant event gave millions of patients with diabetes not only the opportunity to live, but also the hope that their life with this disease would be full.

The article examines the history of insulin discovery, as well as the evolution of several generations of insulin preparations and the advantages of each of the generations that have radically changed not only life expectancy, but also its quality.

The first generation - insulins of animal origin and the solution of the first tasks of their sufficient production and purification. The next generation is human insulins, the purification of which was also a problem. The third generation is insulin analogues, the action of which became closer to the action profile of natural insulin. And the last generation - insulin analogues, most closely mimicking the action of endogenous insulin.

Along with the development of insulin preparations, the article traces the evolution of the devices of its administration.

KEYWORDS: insulin; 100 years; analogues

\section{БАНТИНГ И КОЛЛЕГИ}

Меньше года осталось до знаменательной даты в истории - даты открытия и начала применения инсулина. Важность этого события выходит далеко за рамки клинической диабетологии и имеет большое значение как для медицины, так, пожалуй, и для всего человечества. Открытие и начало применения инсулина на рубеже 1921-1922 гг. позволило миллионам больных сахарным диабетом не просто получить избавление от быстрой и мучительной смерти, но и приобрести возможность жить долго и счастливо. Конечно, все, кто занимался и занимается вопросами лечения сахарного диабета, прекрасно знают, что прошло еще много десятилетий, прежде чем качество и продолжительность жизни лю- дей, нуждающихся в инсулине, стали действительно приближаться к жизни людей, не имеющих этого заболевания, но те далекие события не становятся от этого менее значимыми.

В преддверии столетнего юбилея мы вспоминаем и отдаем дань уважения работам канадских врачей Фредерика Бантинга и Чарльза Беста и чуть позднее присоединившихся к ним Джона Маклеода и Джеймса Коллипа.

В последние месяцы 1921 г. после серии опытов Бантингу и его помощнику Бесту удалось добиться удивительного результата. После выделения из ткани поджелудочной железы экстракта его введение собаке по имени Маржори с удаленной поджелудочной железой позволило снизить уровень сахара в крови и предотвратить гибель животного (рис. 1) [1]. 


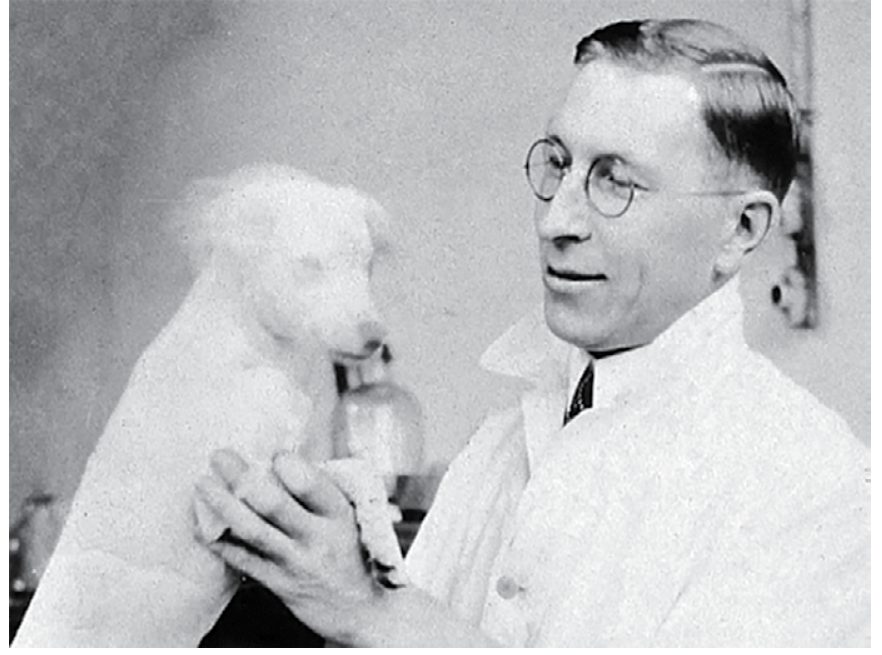

Рисунок 1. Доктор Бантинг и собака Маржори (фото из открытых источников).

Такой обнадеживающий результат позволил ученым решиться на введение очищенного экстракта (максимально по тем временам возможного) первым пациентам, находившимся в терминальной стадии заболевания сахарным диабетом. История предоставляет нам документально подтвержденное упоминание, датированное 22 января 1922 г., о первом пациенте Леонарде Томпсоне, 14 лет (фотография ребенка перед первой инъекцией и через 3 нед после начала лечения с тех времен фигурировала во всех учебниках эндокринологии) (рис. 2).

Конечно, история изучения возникновения сахарного диабета и его последствий началась намного раньше, и можно было бы вспомнить многие имена ученых и врачей-энтузиастов, которые внесли значительный вклад в изучение эндокринной физиологии и патологии поджелудочной железы. Но отдельно хочется упомянуть как минимум три имени. Это, конечно, Пауль Лангерганс, изучавший гистологию поджелудочной железы. Его заслуги были высоко оценены современниками, и, как мы знаем, островки скопления клеток, вырабатывающих вещество, влияющее на уровень сахара в крови, в последующем были названы в его честь. Кроме того, другой немецкий ученый Оскар Минковский доказал, что появление сахара в моче развивается после удаления поджелудочной железы. И наконец, наш отечественный ученый Леонид Соболев (ученик Ивана Павлова) внес значительный вклад в изучение морфологии поджелудочной железы и ее роли в развитии диабета.

\section{ЭРА ЖИВОТНЫХ ИнСУЛИНОВ}

Итак, Бантинг и его коллеги показали всему миру спасительные свойства экстракта поджелудочной железы для первых десятков пациентов. После таких обнадеживающих результатов для большого числа пациентов с сахарным диабетом 1 типа встал вопрос о массовом производстве, которое было не под силу никаким отдельным ученым и врачам-энтузиастам.

В этот период две компании: американская «Эли Лилли» и чуть позднее датская «Нордиск Инсулинлабораториум» быстро и эффективно запустили процесс коммерческого производства инсулина из животного сырья. Конечно, в те годы процесс очистки инсулина от примесей оставлял желать лучшего. Из-за примесей у многих пациентов возникали выраженные местные реакции, а в местах инъекций быстро развивались липодистрофические явления [2]. Тем не менее проблема сохранения жизни перестала быть такой острой. Состоялся огромный прорыв в лечении смертельного до этого момента заболевания - сахарного диабета...

Первые 20 лет инсулин извлекали из животного сырья и использовали исключительно инсулины короткого действия, что, во-первых, было неудобно, потому что приходилось делать не менее 4-6 инъекций такого инсулина в сутки. Кроме того, из-за недостаточной очистки от примесей очень быстро возникали липодистрофические изменения (как по гипертрофическому, так и атрофическому варианту), нарушался процесс всасывания, создавая дополнительные проблемы в контроле
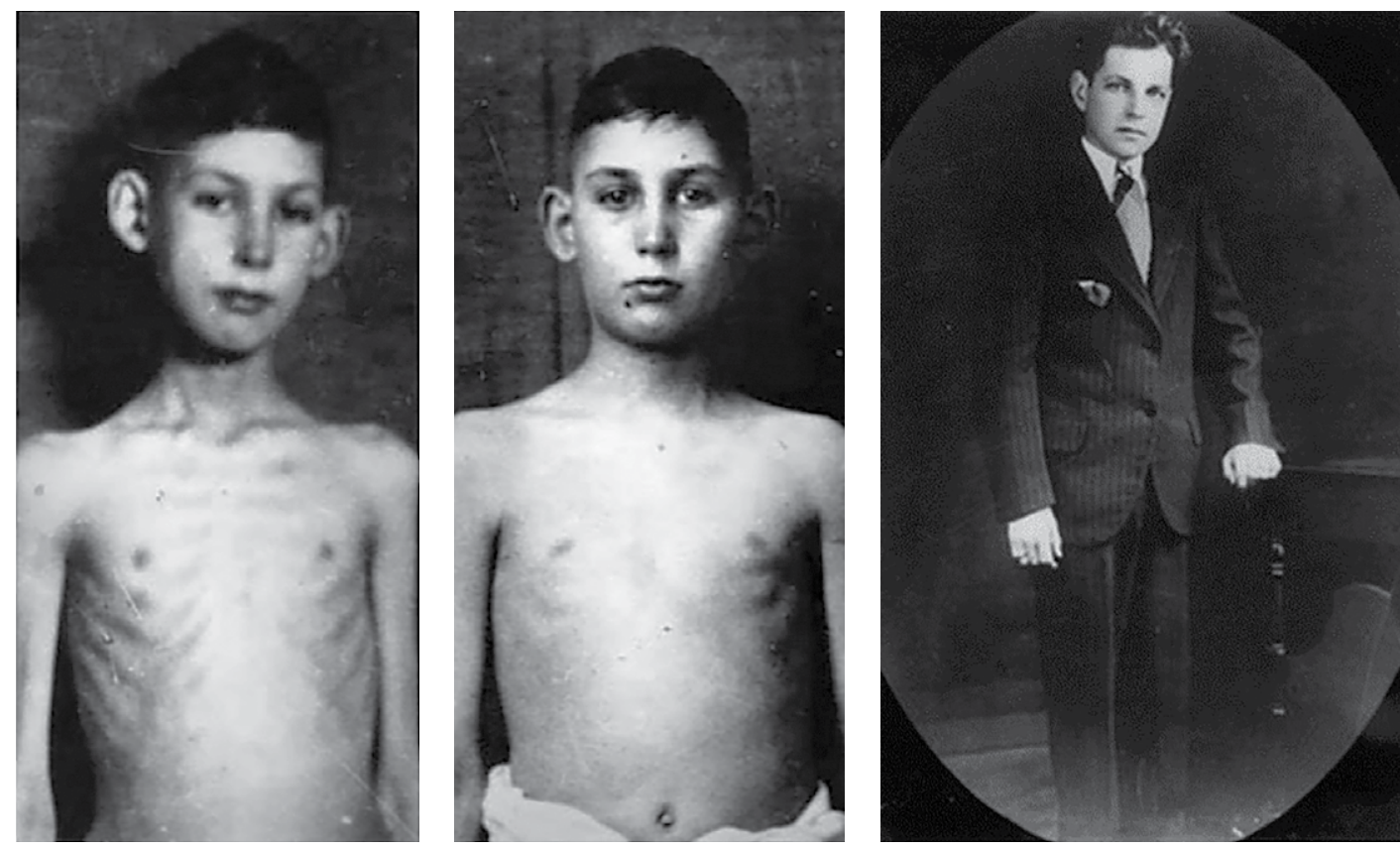

Рисунок 2. Леонард Томпсон до, во время лечения и по прошествии времени (фото из открытых источников). 
за уровнем сахара в крови [3]. Не следует забывать, что в те времена качество игл для введения оставляло желать лучшего, это также способствовало развитию как липодистрофических, так и других местных реакций и последствий.

Стоит особо подчеркнуть важность создания первого инсулина длительного действия. Это сделал датский ученый Ганс Хагедорн, а инсулин, созданный им с использованием протамина в виде пролонгатора, был назван Нейтральный Протамин Хагедорна (НПХ). С момента его массового внедрения в 1946 г. следующие примерно 50 лет это был самый применяемый инсулин в мире.

Когда коммерческое производство инсулинов стало превращаться в рутинный процесс, остро встал вопрос о качестве очистки инсулина от различных примесей, поскольку используемый инсулин тогда получали из поджелудочных желез животных (коров, свиней и даже кашалота). Инсулины именно этих животных были наиболее близки по аминокислотной последовательности к инсулину человека. В этом плане наибольшим сходством обладает свиной инсулин, состоящий из 52 аминокислот. Он отличается по составу от человеческого инсулина только одной аминокислотой.

Основным загрязняющим веществом коммерческих инсулинов животного происхождения являлся проинсулин (предшественник инсулина). Поэтому с годами качество очистки инсулиновых препаратов стали определять по количеству молекул проинсулина на 1 миллион молекул чистого вещества. Появился специальный количественный показатель ppm (particles per million, частиц на 1 миллион). Но только к 70-м годам прошлого века технологии достигли такого уровня, когда удалось добиться, чтобы этот показатель составил $\leq 10$ ppm. Такая чистота препарата стала называться «монокомпонентной степенью очистки» (МС). Если на флаконах тех времен можно было увидеть после названия инсулина эти две буквы, значит, пациенту вводили самый чистый и лучший по тем временам инсулин.

\section{ОТ ЖИВОТНЫХ ИНСУЛИНОВ К ИНСУЛИНАМ ЧЕЛОВЕКА}

Уже во второй половине прошлого века стало очевидным, что быстро растущая общемировая потребность в инсулине скоро не сможет быть удовлетворена производимыми из животного сырья препаратами. Быстро росло число пациентов с сахарным диабетом 1 типа, а кроме того, все шире инсулин стал назначаться больным с сахарным диабетом 2 типа после значительной длительности болезни. Наряду с этим, ведущие специалисты понимали, что используемый многие годы белок, чужеродный собственному человеческому (пускай и отличающийся всего на 1 аминокислоту), - это не оптимальный вариант терапии.

Как только технологии позволили изменить ситуацию, одной из первых белковых молекул, которых это коснулось, стал как раз инсулин. Сначала, в самом конце 1970-х годов, была разработана технология ферментативной обработки свиного инсулина с заменой единственной аминокислоты, не соответствующей полной аминокислотной последовательности инсулина человека (треонин у человека и аланин у свиньи в положении
В30). Таким образом, впервые синтетическим образом был получен человеческий инсулин. Но при этом оставалась привязка к источнику сырья - поджелудочным железам животных.

В первой половине 1980-х годов, когда появились технологии генной инженерии, в качестве продуцента стали использовать генно-модифицированные штаммы дрожжей или кишечной палочки. При этом стали получать не просто человеческий генно-инженерный инсулин. Но, благодаря новейшим методам очистки, инсулин, практически свободный от примесей. Поэтому на производимых флаконах, а впоследствии и пенфиллах, после названия препарата появились две новые буквы НМ (Human Monocomponent). Что означало - во флаконе (или пенфилле) находится человеческий инсулин монокомпонентной степени очистки. Инноваторами этих технологий опять стали две компании, уже упоминавшиеся выше, — «Эли Лилли» и «Ново Нордиск».

\section{СРЕДСТВА ДОСТАВКИ ИНСУЛИНА}

Хотя средства введения (или доставки) как будто не связаны напрямую с самим инсулином и его свойствами, но о них также следует упомянуть, поскольку они не только явили собой отражение общего прогресса в лечении, но и значительно повлияли на качество жизни миллионов пациентов, каждый день которых связан с инъекциями.

В первую очередь стоит упомянуть созданную в 1985 г. шприц-ручку, где емкость для введения инсулина (получившая название пенфилл) была в патроне/гильзе. Она помещалась в полости ручки, а нажимная кнопка позволяла за одно нажатие вводить 2 Ед инсулина. Данная шприц-ручка была создана компанией «Ново Нордиск» (рис. 3). Примечательно, что вместе с ручкой в комплекте была впервые представлена атравматичная и асептическая игла специальной заточки, намного более тонкая, чем все предшествующие типы игл (толщиной всего лишь 27G) [4].

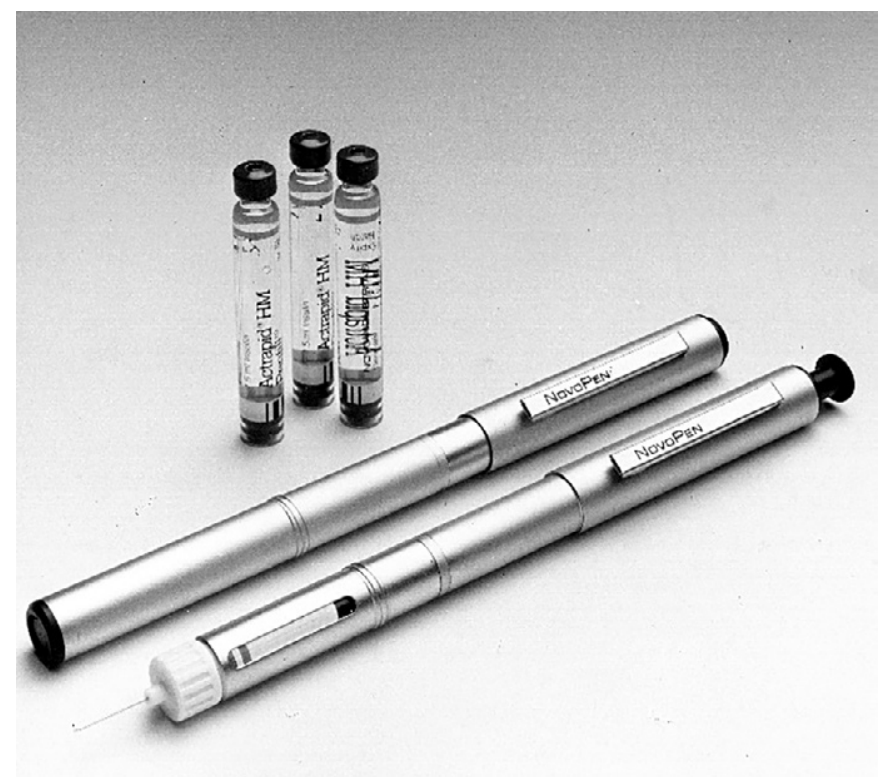

Рисунок 3. Первая шприц-ручка «НовоПен» (фото из открытых источников). 


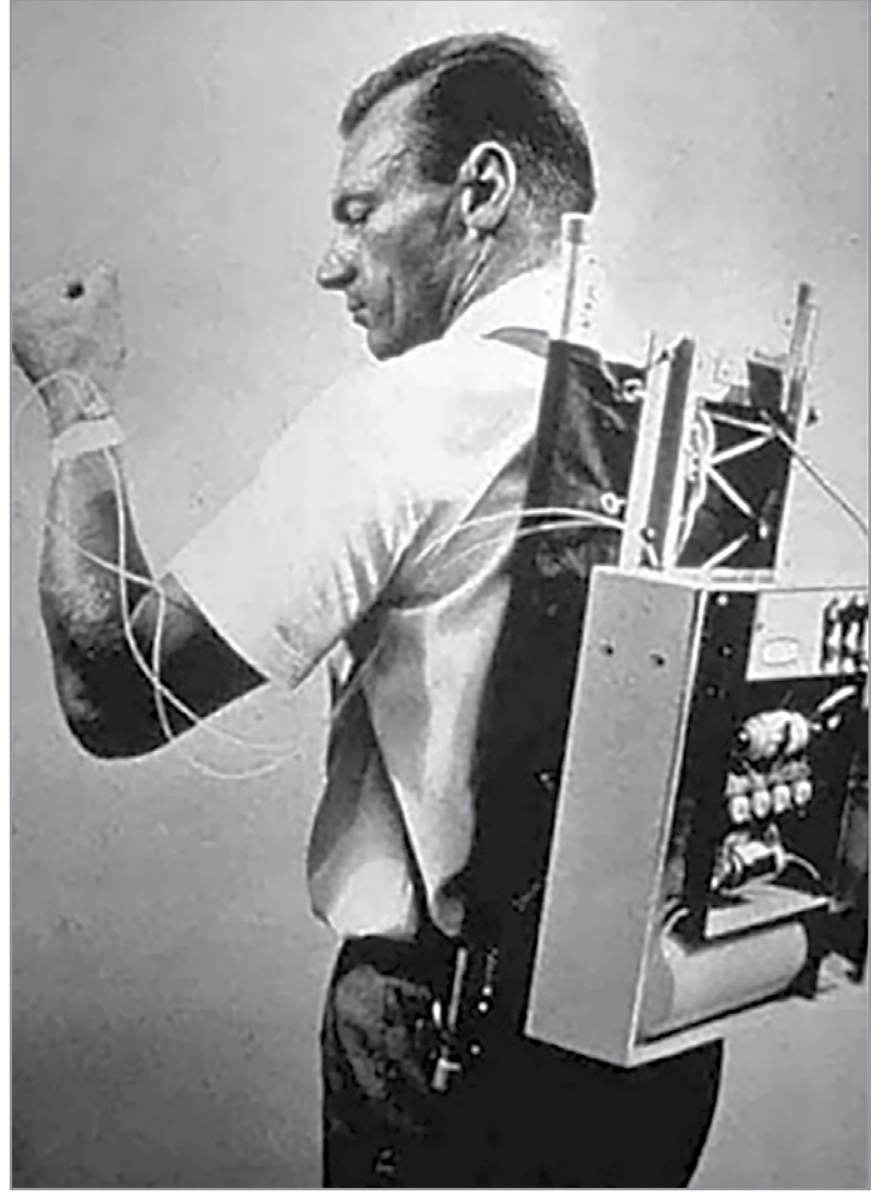

Рисунок 4. Первая инсулиновая помпа доктора Кадиша (фото из открытых источников).

В эти же 1980-е годы распространение стали получать инсулиновые портативные дозаторы инсулина, так называемые инсулиновые помпы, где основным лидером производства была компания «МиниМед». Потребовалось около 20 лет, чтобы от первой помпы, изобретенной доктором Кадишем, которая была размером с большой рюкзак, прийти к портативному устройству (рис. 4). Эта альтернативная режиму множественных инъекций система стала очень удобной и довольно надежной и полюбилась многим врачам и пациентам [5].

\section{АНАЛОГИ ИНСУЛИНА ЧЕЛОВЕКА}

Через 10-15 лет массового внедрения человеческих монокомпонентных инсулинов, несмотря на видимую идеальность применяемого лекарственного воздействия, - возмещение абсолютной (при сахарном диабете 1 типа) или относительной (при сахарном диабете 2 типа) инсулиновой недостаточности препаратами, полностью идентичными эндогенному инсулину, стали очевидны некоторые недостатки такого лечения. Главный среди них - это, конечно, нефизиологический способ доставки экзогенного инсулина и отсутствие этапа прохождения через печень, а также невозможность мгновенного начала его эффекта после подкожного введения. В то время как в здоровом организме секретируемый бета-клетками инсулин поступает сначала в печень и начинает действовать буквально через 2-3 минуты.
Поэтому, как следствие нефизиологического способа доставки инсулина, у большинства пациентов регистрировались частые гипогликемии, перепады гликемии в течение суток, отсутствие предсказуемости действия инсулинов даже при условии введения одинаковой дозы и схемы терапии изо дня в день.

Решение пришло сначала в виде гипотезы, а затем в виде разработки и внедрения в клиническую практику так называемых аналогов инсулина. Ноу-хау этого нового поколения инсулинов отличались у различных компаний, но принципы были схожими.

Во-первых, изменение в аминокислотной последовательности должно привести либо к ускорению времени начала действия и более сокращенному времени действия инсулина (для инсулинов короткого действия), либо, наоборот, более длительному, плавному и, в идеале, беспиковому действию (для инсулинов продленного действия) [6].

Во-вторых, изменение должно быть безопасным с точки зрения онкогенности и тератогенности.

В-третьих, изменение в аминокислотной последовательности не должно затрагивать те аминокислотные участки, которые отвечают за реализацию эффекта молекулы инсулина на уровне рецепторов клеток органов-мишеней.

Самым первым аналогом, зарегистрированным для применения в практике, оказался аналог инсулина короткого действия лизпро («Эли Лилли», 1995), а первым аналогом инсулина длительного действия стал гларгин 100 («Санофи», 2000).

В настоящее время в большинстве стран инсулиновые аналоги этой генерации являются самыми распространенными инсулинами в мире, а выпускаются они различными компаниями, включая отечественных производителей.

\section{СЛЕДУЮЩЕЕ ПОКОЛЕНИЕ АНАЛОГОВ ИНСУЛИНА}

Десятилетие, которое только что закончилось, ознаменовалось дальнейшими шагами по усовершенствованию возможностей препаратов инсулина. Идеология создания инсулинов аналогового ряда продолжила свое развитие.

Во-первых, были созданы два аналога, продолжительность действия которых больше 24 ч. Но главная их особенность - это ровный профиль действия, что заметно снижает риск любых гипогликемий по сравнению с аналогами инсулина предыдущего поколения. Это инсулин деглудек («Ново Нордиск», 2013) с длительностью действия 42 ч и более [7] и инсулин гларгин 300 ЕД/мл («Санофи», 2017) с длительностью действия около 36 ч [8].

Во-вторых, появился аналог инсулина сверхбыстрого действия Фиасп, характеризующийся более ранним началом действия и более сильным сахароснижающим эффектом в первые 30 минут по сравнению с аналогом инсулина короткого действия предыдущего поколения - инсулином аспарт [9].

Таким образом, в настоящее время мы можем говорить об истории открытия и создания различных препаратов инсулина как истории 4 поколений препаратов: где I поколение - это животные инсулины, II - это инсулины человека, III поколение - это аналоги инсулина 


\section{ЭВОЛЮЦИЯ ПРЕПАРАТОВ ИНСУЛИНА}

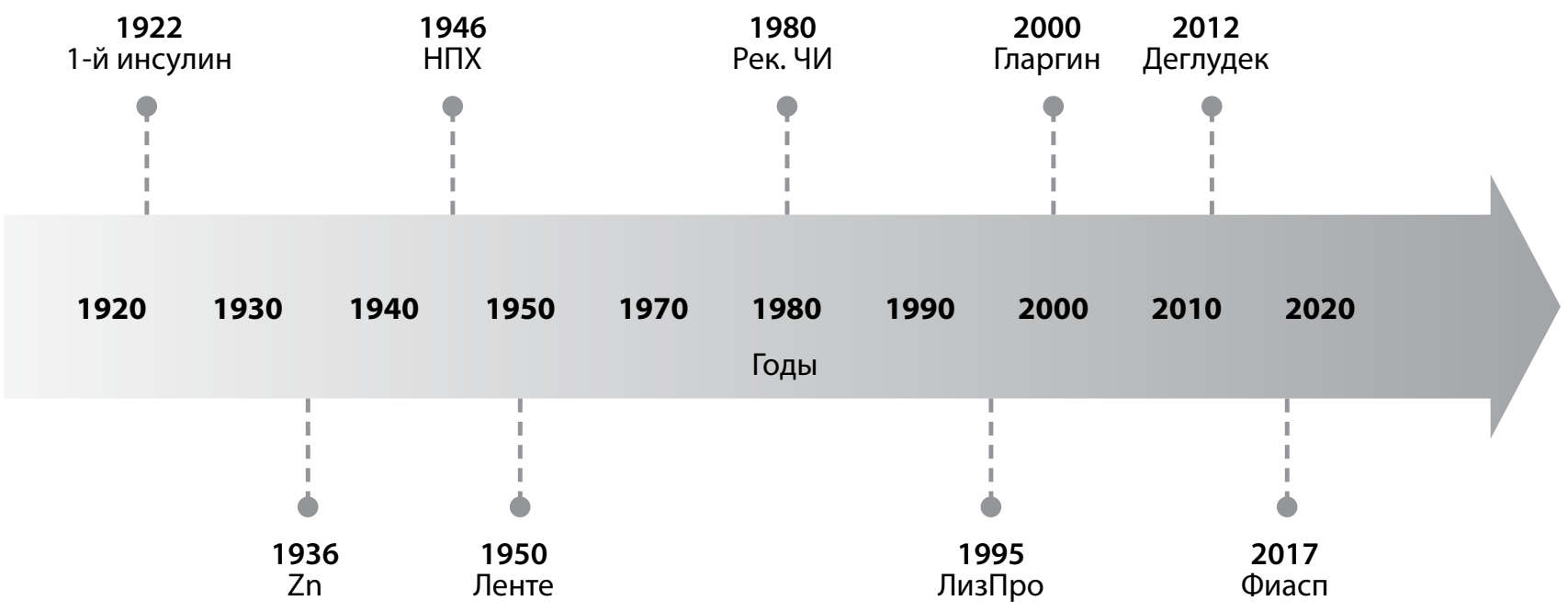

Рисунок 5. Эволюция препаратов инсулина.

и IV поколение - это современные аналоги инсулина, действие которых максимально приближено к профилю действия природного инсулина в здоровом организме человека.

Хотелось бы также, знаменуя приближение исторической даты, вспомнить всю хронологию, которая началась практически 100 лет назад с Бантинга, и как она эволюционировала до настоящего времени (рис. 5):

1921 г. - открытие инсулина Ф. Бантингом и Ч. Бестом;

1922 г. - первые инъекции инсулина человеку;

1922-1923 гг. - начало массового коммерческого производства инсулина;

1946 г. - начало массового применения пролонгированного инсулина НПХ;

1970 г. - достигнута очистка инсулинов $\leq 10$ ppm (МС-инсулины);

1978-1980 гг. - разработка и внедрение идеологии базис-болюсной терапии;

1980-1982 гг. - первые генно-инженерные человеческие инсулины (НM);

1963-1964 гг. - первая инсулиновая помпа;

1980-е гг. — первые коммерческие инсулиновые помпы; 1985 г. - первая инсулиновая шприц-ручка;

1995 г. - первый аналог инсулина короткого действия лизпро;

2000 г. - первый аналог инсулина длительного действия гларгин;

2012 г. - первый аналог сверхдлительного действия деглудек;

2017 г. - первый аналог инсулина сверхбыстрого действия Фиасп;

2020 г. - первый отечественный биоаналог инсулина.
История учит нас, что прогресс в медицине идет семимильными шагами. И, возможно, не за горами то время, когда научный прорыв позволит нам найти замену современной инсулинотерапии.

Уже около 40 лет идут работы по пересадке бета-клеток с параллельной селективной иммуносупрессией их отторжения [10]; по выращиванию иммунологически защищенных стволовых слеток, которые после пересадки реципиенту запрограммированы на преобразование в бета-клетки [11]; по полной пересадке поджелудочной железы: активно разрабатываются системы замкнутого контура в помповой инсулинотерапии и другие технологии $[12,13]$.

А пока мы вспоминаем первопроходцев во главе с Бантингом, а также все эти сто лет важнейших открытий, благодаря которым уже сейчас стала реальностью давняя мечта ученых, врачей и пациентов о том, чтобы жизнь больных сахарным диабетом не отличалась от жизни обычных людей

\section{ДОПОЛНИТЕЛЬНАЯ ИНФОРМАЦИЯ}

Финансирование работы. Работа выполнена за счет личных средств авторского коллектива.

Конфликт интересов. Авторы декларируют отсутствие конфликта интересов, связанных с публикацией настоящей статьи.

Вклад авторов. Шестакова М.В. - обзор публикаций по теме статьи, написание текста рукописи; Дедов И.И. - редактирование, проверка критически важного содержания, утверждение рукописи для публикации. Все авторы внесли существенный вклад в проведение исследования и подготовку статьи. 


\section{СПИСОК ЛИТЕРАТУРЫ | REFERENCES}

1. Дедов И.И., Шестакова М.В. Сахарный диабет типа 1: реалии и перспективы. М.: МИА; 2016. [Dedov II, Shestakova MV. Sakharnyi diabet tipa 1: realii i perspektivy. M.: MIA; 2016. (In Russ.)].

2. Rowe $\mathrm{AH}$, Garrison $\mathrm{OH}$. Lipodystrophy: atrophy and tumefaction of subcutaneous tissue due to insulin injections. JAMA. 1932;99:16-18.

3. Hildebrandt P. Subcutaneous absorption of insulin in insulindependent diabetic patients. Influences of species, physico-chemical properties of insulin and physiological factors. Dan Med Bull. 1991;38(4):337-346

4. Hyllested-Winge J, Sparre T, Kynemund Pedersen L. NovoPen Echo ${ }^{\circledast}$ insulin delivery device. Med Devices (Auckl). 2016;9:11-18 doi: https://doi.org/10.2147/MDER.S59229.

5. Shah R, Patel M, Maahs D, Shah V. Insulin delivery methods: Past, present and future. Int J Pharm Investig. 2016;6(1):1 doi: https://doi.org/10.4103/2230-973X.176456

6. Heise T, Nosek L, Ronn BB, et al. Lower Within-Subject Variability of Insulin Detemir in Comparison to NPH Insulin and Insulin Glargine in People With Type 1 Diabetes. Diabetes. 2004;53(6):1614-1620. doi: http://doi.org/10.2337/diabetes.53.6.1614

7. Дедов И.И., Шестакова М.В. Инсулин деглудек - новый аналог инсулина сверхдлительного действия // Сахарный duaбem. - 2014. - T. 17. — №2. - C. 91-104. [Dedov II, Shestakova MV. Insulin degludec is a new ultra-long-acting insulin analogue. Diabetes mellitus. 2014;17(2):91-104 (In Russ.)]. doi: https://doi.org/10.14341/DM2014291-104

8. Becker RH, Dahmen R, Bergmann $\mathrm{K}$, et al. New insulin glargine 300 Units/mL-1 provides a more even activity profile and prolonged glycemic control at steady state compared with insulin glargine 100 Units/mL-1. Diabetes Care. 2015;38(4):637-643. doi: https://doi.org/https://doi.org/10.2337/dc14-0006

9. Davis A, Kuriakose J, Clements JN. Faster Insulin Aspart: A New Bolus Option for Diabetes Mellitus. Clin Pharmacokinet. 2019;58(4):421-430. doi: https://doi.org/10.1007/s40262-018-0696-8

10. Дедов И.И., Балаболкин М.И. Возможности и проблемы трансплантации бета-клеток поджелудочной железы при сахарном диабете // Сахарный диабет. - 2005. T. 8. - №2. - C. 42-52. [Dedov II, Balabolkin MI. Vozmozhnosti i problemy transplantatsii beta-kletok podzheludochnoy zhelezy pri sakharnom diabete. Diabetes mellitus. 2005;8(2):42-52. (In Russ.)]. doi: https://doi.org/10.14341/2072-0351-5781

11. Пеллегрини С., Сарди В., Пьемонти Л. Замещение бетаклеток поджелудочной железы при сахарном диабете // Сахарный диабет. — 2013. - Т. 16. — № 3. - C. 11-20. [Pellegrini S, Sordi V, Piemonti L. Beta-cell transplantation in diabetes mellitus. Diabetes mellitus. 2013;16(3):11-20 (In Russ.)] doi: https://doi.org/10.14341/2072-0351-812

12. Kovatchev BP, Breton M, Man CD, Cobelli C. In silico preclinical trials: a proof of concept in closed-loop control of type 1 diabetes. J Diabetes Sci Technol. 2009;3(1):44-55. doi: https://doi.org/10.1177/193229680900300106

13. Kesavadev J, Saboo B, Krishna MB, et al. Evolution of Insulin Delivery Devices: From Syringes, Pens, and Pumps to DIY Artificial Pancreas. Diabetes Ther. 2020;11:1251-1269. doi: https://doi.org/10.1007/s13300-020-00831-z

\section{ИНФОРМАЦИЯ ОБ АВТОРАХ [AUTHORS INFO]}

* Шестакова Марина Владимировна, д.м.н., профессор, академик PAH [Marina V. Shestakova, MD, PhD, Professor]; адрес: 117036, Москва, ул. Дм. Ульянова, д. 11 [address: 11 Dm. Ulyanova street, Moscow, 117036 Russian Federation]; ORCID: https://orcid.org/0000-0002-5057-127X; eLibrary SPIN: 7584-7015; e-mail: nephro@endocrincentr.ru

Дедов Иван Иванович, д.м.н., профессор, академик PAH [Ivan I. Dedov, MD, PhD, Professor]; ORCID: https://orcid.org/0000-0002-8175-7886; eLibrary SPIN: 5873-2280; e-mail: dedov@endocrincentr.ru

\section{ЦИТИРОВАТЬ:}

Дедов И.И., Шестакова М.В. К столетию открытия инсулина // Сахарный диабет. - 2021. - Т. 24. — №1. - С. 11-16. doi: https://doi.org/10.14341/DM12733

\section{TO CITE THIS ARTICLE:}

Dedov II, Shestakova MV. On the centenary of the insulin discovery. Diabetes Mellitus. 2021;24(1):11-16. doi: https://doi.org/10.14341/DM12733 